\title{
Coordinated Resource Management Models in Hierarchical Systems
}

\author{
Gabsi Mounir \\ Department of Computer Sciences, \\ Higher Institute of Technological \\ Studies, Nabeul,Tunisia
}

\author{
Rekik Ali \\ Department of Computer Sciences, \\ Higher Institute of Technological \\ Studies, Sfax, Tunisia
}

\author{
Temani Moncef \\ University of Tunis, LI3 Laboratory,
} IS

\begin{abstract}
In response to the trend of efficient global economy, constructing a global logistic model has garnered much attention from the industry .Location selection is an important issue for those international companies that are interested in building a global logistics management system. Infrastructure in Developing Countries are based on the use of both classical and modern control technology, for which the most important components are professional levels of structure knowledge, dynamics and management processes, threats and interference and external and internal attacks. The problem of control flows of energy and materials resources in local and regional structures in normal and marginal, emergency operation provoked information attacks or threats on failure flows are further relevant especially when considering the low level of professional ,psychological and cognitive training of operational personnel manager. Logistics Strategies include the business goals requirements, allowable decisions tactics, and vision for designing and operating a logistics system .In this paper described the selection module coordinating flow management strategies based on the use of resources and logistics systems concepts.
\end{abstract}

Key-words- Strategy models; logistic system; resources management; optimisation; routing; transport

\section{INTRODUCTION}

Large distributed real-time embedded systems [1] are often designed with static resource management strategies and tailored for specific goals or missions. These rigid resource allocation strategies are incapable of adapting to changing system goals, resource levels and operating environments. This inability to adapt can cause systems to fail to meet the end-to-end quality of service requirements when conditions change. Strategic management [2] often entails identifying the organization's mission, vision, goals, policies, plans, projects and programs. It also involves defining and allocating resources to manage the organization. Strategic management is also described as an on-going process of assessing, and managing the business [3], watching competitors; reassessing each business regularly and determining the best way to make it succeed.

More effective approach[4], based on the concept of intelligent control, which includes the following components:

- Receiving and processing data from the objects of measurement system;

- Recognition situation in the state space object discrimination and classification;
- Construction of decision tree splitting at the alternative target of the state space systems under the strategy achieving ;

- Logic circuit, the team executive management mechanisms under tactics ;

- Tracking the path system and forecast of possible situations;

- Optimization and adaptation strategies goal-oriented behaviour.

The Company systems are characterised by central planning and control methods, which shows a wide range of weaknesses and cannot fulfil these demands. Conventional planning and control methods are based on simplified premises (predictable throughput times, fix processing times etc.), which lead to an inadequate and unrealistic description of the production system. In case of disturbances or fluctuating demand, centralised planning and control methods are insufficient to deal with the complexity of centralised systems. And this rises disproportionately to their size and heavily constrains the fault tolerance and the flexibility of the overall system. These weaknesses of conventional logistic planning and control systems require a fundamental reorganisation. Recently in scientific research the concept of autonomously controlled logistics systems as an innovative approach of a decentralised planning and control system is investigated, which meets the increasing requirements of a flexible and efficient order processing. To establish the logistic concept of autonomous control, adequate modelling methods are needed systematic models optimization strategy, coordination strategy which allows an exact description of autonomously controlled logistics processes.

\section{EfFective StRategic Models}

Consider the diagram of the performance criteria process formation [5] based on the conception of logistics (Fig .1), as a strategic management function based on logistic criteria, which they are founded on:

- Growth effect through changing the goals.

- growth effect through optimization strategies;

- changing logistics management structure of production and transport structure (PTS);

- rational restructuring components of the logistics system; 
- optimization of logistic functions, processes, method of action according to plans and tactics of behavior, terminal time execution of orders;

- Changing management principles, systematic changes in the structure of production, logistics optimization procedures, information provision of decision making based DSS.

- formulate strategies achieving the goal (local and strategic);

- decomposition strategies tactics and action plans to control the flow of resources (material, energy, information);

- implementation of strategies and tactics through system control commands;

- Control of facilities management before and after the control action.

- Prognosis situations scenarios based of events.

- Forming logistics strategic goals.

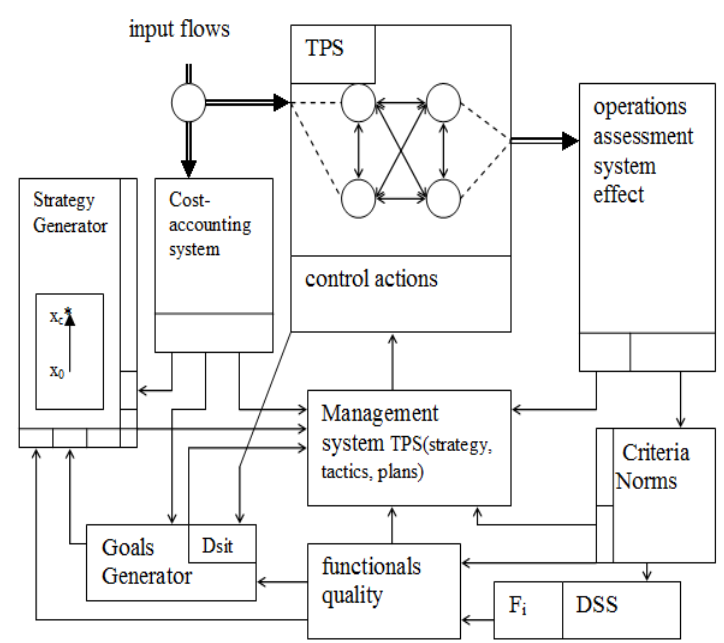

Fig 1. Scheme of formation of management under quality criteria and selection strategies

\section{Systematic Optimization Strategy Models}

Extension and complexity of hierarchical structures have created a number of logistical, resource, information, knowledge training, psychological and cognitive problems that lead to disorientation commands and false solutions, respectively, leading to the collapse of the system, crises, accidents, disasters, technological and managerial nature.

The effectiveness of the system strategies based on:

- optimizing the hierarchical structure according to purpose;

- optimization of strategic reserves by local plans and objectives;

- Adaptation and optimization algorithms for processing data streams in the system feedback and hierarchical levels of data exchange;

- systematic evaluation functions, resources cost optimization , personnel, information resources;
- formation of coordination strategies on the upper level and the optimal strategies that connect all levels of the hierarchy;

- synthesis management strategies according to criteria of quality and minimize costs;

All these approaches to optimal resource management systems are based on the system analysis of quantitative and qualitative indicators functioning of all hierarchy levels, integrating management programs, improving the structure and management strategy.

Systematic approach to formulate strategies characterized conditions:

- main strategy is related with functional all levels of the hierarchy;

- Strategy connects all levels of the hierarchy and all business sectors;

Accordingly is formed procedure decomposition of global strategy at local target selection by the management team [5]:

- integration strategy functions processes at all levels of the hierarchy;

- strategy of consolidating resources;

- strategies to minimize inventory and maximize the production and services;

- strategy to reduce the production cycle;

- strategy of differentiating service flow of orders;

- strategy cooperation in the logistics chain;

- logistics strategy, research, information and knowledge oriented innovation;

- Logistics outsourcing strategy.

For specifics transport resource transportation should consider such as [6]:

- backup strategy and calculation of transportation;

- Strategic logistics planning and supply chain ;

- development of information and telecommunication systems, navigation routes of control in normal and emergency situations;

- Strategy to Synchronized Resource Planning or Flow Planning (MRPIII).

\section{Information Resource Management StRATEgIC}

Development of crisis at present, functioning of industrial and socio-administrative structures indicates poor performance management strategies in both the global and the local scales.

Information can add value to your products and services. Improved information flows can improve the quality of decision making and internal operations. Yet, many managers do not fully understand the real impact of information - the cost of a lost opportunity, of a poor product and of a strategic mistake - all risks that can be reduced using the appropriate information.

Accordingly, it is necessary to identify components of influence in decision-making information and cognitive nature: 
- Insufficient training of personnel manager, which leads to misunderstanding content change scenarios of events and incorrect actions.

- inability to clearly logically build tactics and action plans under stress, crisis and conflicting situations;

- global and local goals conflict and strategies for their implementation;

- mobilization of intellectual and information resources through coordination management strategies at all levels of the hierarchy;

- Ability to identify critical signs of crisis.

Formulation and subsequent implementation of coordination and sourcing agreement require appropriate conditions $[1,7]$, which include:

- Availability of local and global strategy at all levels of the hierarchy and executions;

- changes in the structure of production and transportation systems by logistics strategies;

- vertical integration of logistics;

- systematic structuring of resource flows and assessment of their dynamics and control;

- compliance information systems processing data flow dynamics and dynamic situations in the system with the aim of forming correct states of the situations in the state space, target, terminal;

- compliance management strategies tools and hardware and software management system processes in MTC;

- Availability of suitably qualified personnel and mental goal-orientation;

- presence of a strong base professional and fundamental knowledge;

- A computer system supporting decision-making;

- Integration of computer software logistics processes and automated process control based <MRP, DRP, EDI $>$ and <CAD, CAM, CIM, ACU>;

- System integration processes for data collection at all levels of the hierarchy and displayed in 3D-space multimedia center operational management resource streams.

General functions of logistics information while preparing control solutions [15]:

- organizing a network of communication between customers, suppliers and MTC;

- planning operations by tactics and strategy;

- Coordination of logistics;

- monitoring of resource flows;

- control of orders;

- monitoring of external systems and evaluation of dynamic situations;

Under this approach, provides effective solutions suitable to the market situations and resources capable of withstanding crises and information attacks and ground creating information networks for the exchange of data flows in the hierarchy of the system and its environment.

\section{INTEGRATION OF INFORMATION AND NAVIGATION CARTOGRAPHIC SYSTEMS}

To integrate in this, information systems must comply with the principles of [10]:

- coordination of hardware and software modules;

- synthesis ICS based deployment phases;

- coordination places docking telecommunication and computer networks;

- providing structural flexibility of the information system in AMS;

- principle of access to information dialogue rules-based priorities;

- harmonization of methods and means of data packets transmission;

- Information coordination of local and strategic data networks;

- Openness functioning ICT networks and satellite navigation systems.

In integrated systems [7] are updated requirements for the operational management of material resource flows, which requires support of parallelism in time material and information flows, the collection, processing and transmission flow and packets in real time based technologies (EDI) and identification $(\mathrm{AI})$.

An important effect of the functioning of the integrated systems is the ability to manage localized resources stocks selected according to coordinating strategies.

Openness information system for clusters of customers, suppliers, and operational agents helps to create an integrated logistics information system, which is the basis for management the logistics chain flow of resources and information flows for economic calculations. Information Logistics provides the functions of strategic management and coordination [1-8] resource and information flows in the hierarchy of the system connects the logistic chain into a single structure. Accordingly, it is the basis for logistics information structures (LIS).

SIF - System perturbing factors influence $\left(F_{1} \ldots F_{n}\right)$ with stochastic dynamics, $\left(\mathrm{SR}_{\mathrm{V}}\right)$ - sources resources, TOM technological object management, IMS - Information measuring system , ACS - Automated control system , SPStorage products and resources ,UR - User resources ,FOsit $\left(\tau_{\mathrm{i}}\right.$ )- formation of situation state on time $\tau_{\mathrm{i}}$.

Phase of separation of the logistics activities systems, according to the strategic goals, can isolate building blocks [18]:

- IACS - Integrated system of automated management;

- block collection and storage of information;

- block data processing and analysis of the content;

- Informative block preparation decisions.

Accordingly, functional blocks of logistics infrastructure can be represented in the form (Fig .3). 


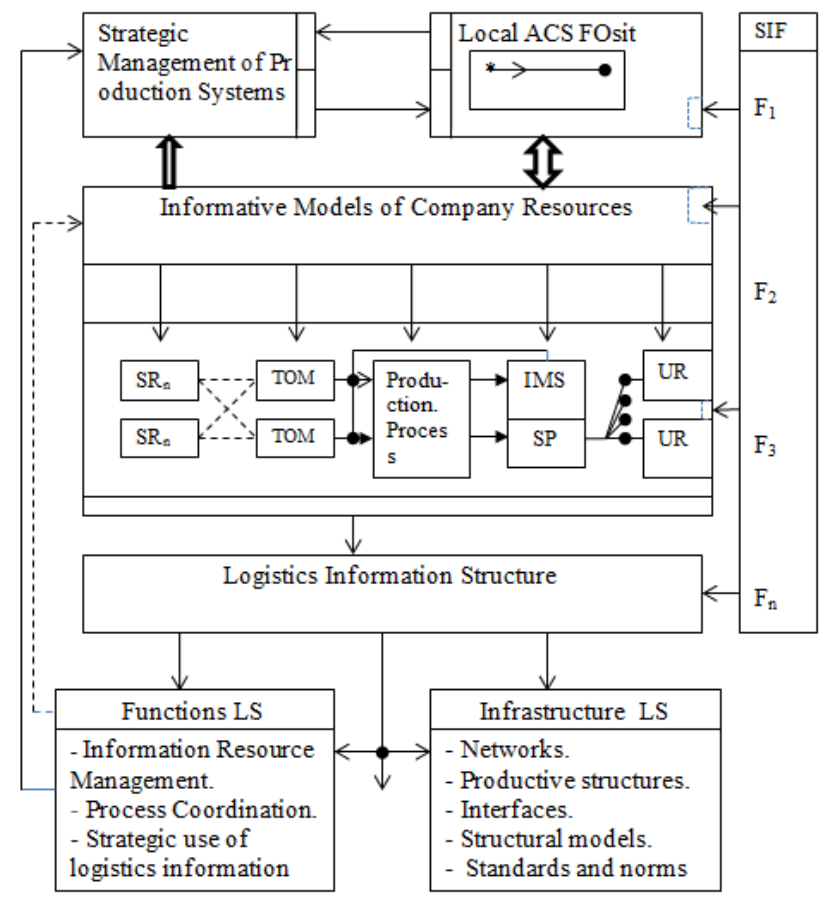

Fig 2. Scheme of structuring logistics information management schemes active resources.

\section{CoORdination Strategies}

Coordination strategy is based on the verification of the situation according to the purpose of the system [8]:

- the situation in the state space;

- the situation in the target area;

- the situation in the terminal area;

- Evaluation and ranking of object trajectory in the state space;

- Assessment coordinates the route and determine the distance to the target;

pattern matching situations in state space, target, terminal and their projection on the route map to determine the degree of approximation to the area of the target state based coordination strategy;

Evaluation criteria for effective routes held by strategic framework of region-based coefficient $\mathrm{CV}$ center of mass (center of influence) [5]:

$$
\underset{T_{i}}{\operatorname{opt} C_{V}}=\left[\sum_{i=1}^{n} D_{i} \cdot M_{i}+\sum_{i=1}^{m} d_{i} \cdot S_{i}\right] /\left[\sum_{i=1}^{n} M_{i}+\sum_{i=1}^{m} S_{i}\right]_{<}^{>} C_{n}
$$

where $D_{i}$ - distance to the i-th client, $d_{i}$ - distance to the source resource, $M$ - weight coefficient passengers number, $S_{i}$ - weight of traffic, $C_{n}$ - normative coefficient, $T_{i}$ - terminal time.

The optimization of transport cost is based on selected graph model with $\mathrm{n}$-sources and $\mathrm{m}$-sinks with models $<\left.\left.\vec{x}_{i}\right|_{i=1} ^{n} \stackrel{g_{i j}}{\rightarrow} \vec{x}_{j}\right|_{j=1} ^{m}>$ then [9]:

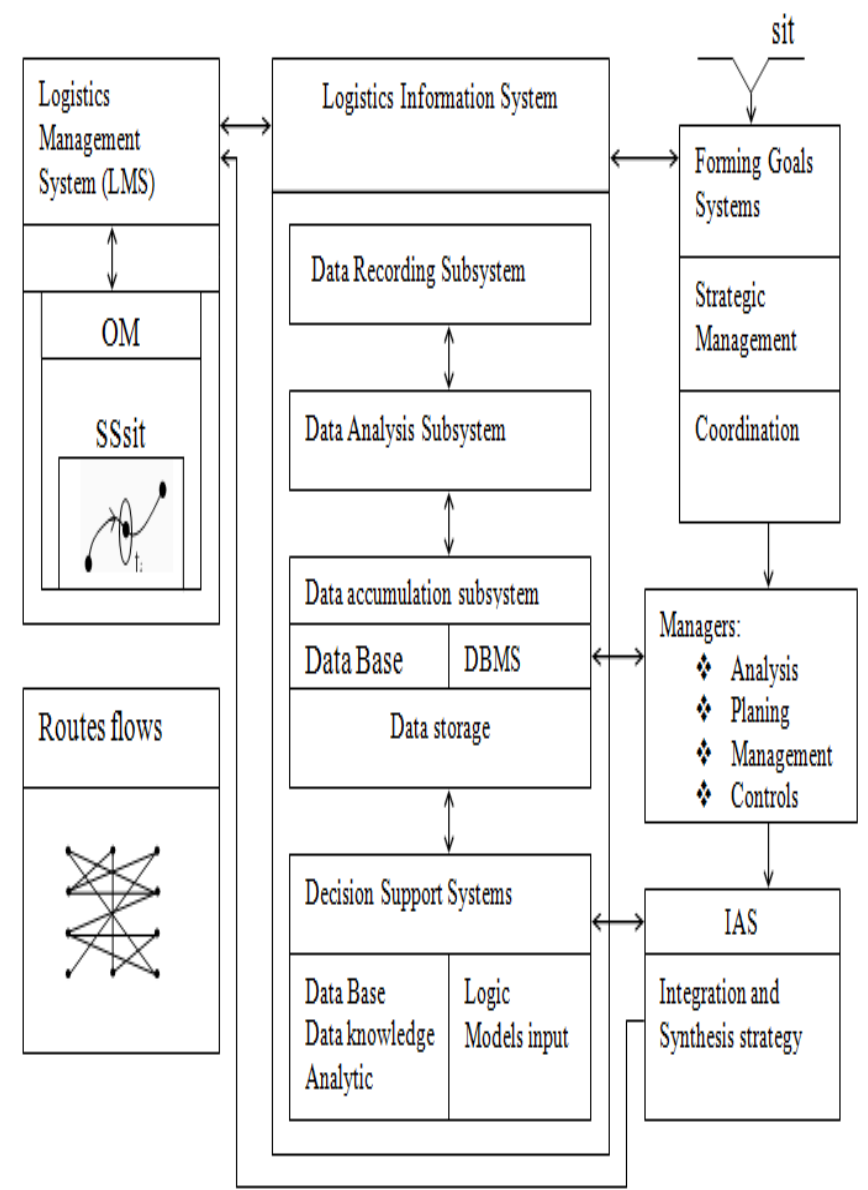

Fig 3. Formation Strategy Coordination

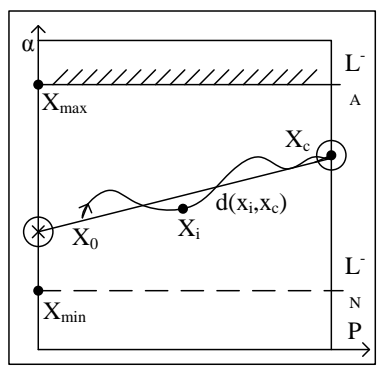

Fig 4.

$$
\sum_{x_{i} \in \Gamma^{-1}\left(x_{j}\right)} \xi_{i j} \leq W_{j}, \forall x_{i} \in \vec{x}
$$

Where $g_{i j}$ - bandwidth arcs, $W_{j}-$ bandwidth vertices, $\xi \mathrm{ij}-$ flow from $\mathrm{xi} \rightarrow x_{j}$.

The itinerary which will win at selected flow management strategy is evaluated by the formula [9], based on tree routes [13] :

$$
g\left(S_{M R}\right)=\prod_{\left(x_{i}, x_{j}\right) \in F} g_{i j} \cdot \prod_{\left(x_{i}, x_{j}\right) \in B} 1 / g_{i j}
$$

Where $\mathrm{F}$ - the set of direct arcs, B - set of reverse arcs.

Optimization of transport cost in the integrity cards routing is based on the procedure of cycle traffic $\mathrm{T}_{(\mathrm{zi})}$. 


$$
V_{z i}=\sum_{i=1}^{n} \sum_{j=1}^{m} C_{i j} \cdot x_{i j} \underset{T_{(z i)}}{\rightarrow} V_{z} \mid \begin{aligned}
& \sum_{i=1}^{n} x_{i j}=a_{i} ; a_{i} \in A \\
& \sum_{i=1}^{n} x_{i j}=b_{i} ; b_{i} \in B \\
& (i, j) \in[1 . . N, M]
\end{aligned}
$$

the performance conditions for volume and cost of each other operations $C_{i j}$ based on the balance of resource flows[12] :

$$
\sum_{i=1}^{n} a_{i}=\sum_{j=1}^{n} b_{j}
$$

To build route systems in cycles $\left\{\mathrm{T}_{(\mathrm{zk}) \mathrm{k}=1, \mathrm{e}}\right\}$, route traffic based matrix and plan transportation problem arising from strategy traffic flows of resources. Used for that number of methods[16]:

Diagonal, lowest cost, potentials, integer methods [6] and conditionally optimal by criteria time, screen models, dynamic linear programming.

Accordingly problem solving scheduling traffic requires one side coordination sequence operations (logistics) and coordination time (synchronization) based scheduling with complete certainty requirements and objectives defined parameters: execution time of the transport operation, passing, expectations and delay.

Under the influence of factors, perturbation regime change and obtain the stochastic nature of the parameters that are probabilistic. For the duration of the transport, resource transactions have introduced mitigation strategies in the form:

$$
\operatorname{Strat}\left[R(t, \tau)_{\Pi D i}\right]=\sum_{i=1}^{n} t_{h}+\sum_{i, j \in T_{m}} \tau_{i j} \rightarrow \min T_{m}(R(t, \tau))
$$

Where $R(t, \tau)_{\Pi D i}$ - during the operation with a sequence of actions $\Pi D_{i}$ on the terminal cycle $T_{m}$ according to the plan of operations.

Optimization plan can be performed based on branch and bound method [14] according to strategy of acceptable choice plan:

$$
\begin{aligned}
& \exists \operatorname{Strat}\left(U \mid C_{T i D i}\right): f\left(C_{i}, x\right) \rightarrow \min F_{\Pi D i}, x \in D \\
& D_{i} \subset G_{O \Pi D_{i}}, i \in 1, k,\left(\bigcup_{i=1}^{k} D_{i}=D\right),\left(D_{s} \cap D_{p}=0, s \neq p\right)
\end{aligned}
$$

(7)

where D - partition into branches sets of plans targeted functional selection strategies, defined as [11]:

$$
I\left(\operatorname{str}\left[R(t, \tau)_{\Pi D i}\right]=\int_{0}^{T_{m}} H_{i}\left(F_{1 i}(t) \ldots F_{n i}(t)\right) d t=o p t T_{m}\right.
$$

Where $\mathrm{F}_{\mathrm{i}}($ ) - Local criteria is forming operational decisions.

Then, the coordination task of integer programming, while the chosen management strategy is formed as:

$$
\begin{gathered}
H_{0}\left(F_{1} \ldots F_{N}\right) \rightarrow \max _{T_{m}} ; \\
H_{m}\left(F_{1} \ldots F_{N}\right) \geq b_{m}, m \in[1, N] ; \\
F_{i} \in Q_{i}(F), i \in[1, N]
\end{gathered}
$$

$Q_{i}(F)$ - area of optimization functional quality.

\section{CONCLUSION}

We have proposed models which evaluate the effectiveness of management strategies resource streams in decision making and internal operations in hierarchical distributed systems. Shown that the optimization procedures are formed on the basis of coordination strategies and structuring routes for resource flows are performed by logistic approach to management tasks. in the paper, there have been determined components, formulas and models logistical coordination strategy in optimization of the transport system company. In our future work, we will try to integrate these models into the system but trying to change the weight of each component of these models according to the strategies chosen by the manager. And we will try to integrate the intelligent agent which is necessary to manage all these models. This problem-solution approach of management resource flows is oriented to the developing countries (Asia, Africa, especially Tunisia).

\section{REFERENCES}

[1] L .A. Belady and C. J. Evangelisti, "System partitioning and its measure," The Journal of Systems and Software, vol. 2, pp. 23-29, 1981.

[2] Karnani, A., "Generic Competitive Strategies," Strategic Management Journal, 5, 1985, pp. 367-80.

[3] Rumelt, Richard P., "Towards a Strategic Theory of the Firm," in R. B. Lamb (ed.), Competitive Strategic Management. Englewood Cliffs, N.J.: Prentice-Hall, 1984, 556-570.

[4] Gabsi Mounir ,Sikora LS ,Model of active Management hierarchical Systems" (CSIT'2009), 15-17 OCTOBER 2009, LVIV, UKRAINE.

[5] krukovski E.V. logistic. -lviv ,Intelligence-West ,2004-416 p.

[6] Simchi-Levi, D., P. Kaminski, and E. Simchi-Levi, 2003, Designing and Managing the Supply Chain: Concepts, Strategies, and Case Studies, 2nd ed., New York: McGraw-Hill Irwin.

[7] krukovski E.V. Logistics management-Lviv.HNU, 2005. - 684 p.

[8] LS Sikora, Systematology decision making in complex technological systems- lviv, kamenyar, 1999. - 380.

[9] Christofides N., Graph theory - the algorithmic approach, Moscow, "Mir",1978. - $431 \mathrm{p}$.

[10] Hu T. programming and flows seyyah - Moscou: Mir, 1974. - 519 p.

[11] Y Phillips, D., Garcia-Diaz A. Methods of analysis of networks Moscow: Mir, 1984. - 496 p.

[12] Stepanek .J.B., Mathematical programming- .: high school, 1977. - 272 $\mathrm{p}$

[13] Fomin G.P., Mathematical methods and models in business: - M: the Finance and statistics, 2001. - 544 p.

[14] Karagodova O.O., Kihel V.P., Rojok V.D. operations Research - K.: ЦУЛ, 2007. - $256 \mathrm{p}$.

[15] Kukushkin NS Conflicts and compromises - M.: Knowledge, 1986. - 31 $\mathrm{p}$.

[16] Aliev, RA, MI Liberzon Methods and algorithms for the coordination of industrial control systems - M.: Radio and communication. 1987. - 206. 